Military Technical College

Kobry Elkobbah,

Cairo, Egypt

April 19-21,2016

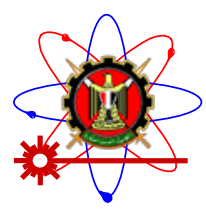

$8^{\text {th }}$ International Conference on

Mathematics and Engineering

Physics (ICMEP-8)

\title{
EM-3
}

\section{A New Method for Parameter Sensitivity Analysis of Chua system}

\author{
Abdel-Azeem Mohamed \\ Faculty of Engineering Pharos University \\ Azima65@hotmail.com
}

\begin{abstract}
The chaos control of parameter -dependent chaotic systems is an important step in many applications. The goal of the control is to stabilize the parameter -dependent chaotic systems . The control parameter is determined through a sensitivity study to obtein the most sensitive parameter that affects the system behavior. The overall system dynamics is governed by the control parameters. The $\mathrm{L}_{2}$ norm is a simple method that determines the most efficient parameter among system parameters. It avoids the disadvantages of the method of sensitivity function approach, such as numerical stability and solving large dimensional system. The results of the study on Chua system show the robustness of the proposed algorithms.
\end{abstract}

1. Introduction

Sensitivity analysis quantifies the dependence of system behavior on the parameters variations that affect the process dynamics. Parametric sensitivity is a simple yet powerful tool to elucidate a system's behavior for use in dynamical analysis, process design, optimization, and control. The sensitivity functions describe the change in the system's outputs due to variations in the parameters that affect the system dynamics. A large sensitivity with respect to a parameter suggests that the system's performance can drastically change with small variations in the parameter[1-3]. Vice versa, a small sensitivity suggests little change in the performance. Knowledge of sensitivities can also help to identify the driving mechanisms of a process without having fully understood the detailed mechanistic interconnections in a large complex system. For these reasons, sensitivity analysis has found wide application in science and engineering,[4-5]. Traditionally, the concept of sensitivity applies to continuous deterministic systems. 
Military Technical College

Kobry Elkobbah,

Cairo, Egypt

April 19-21,2016

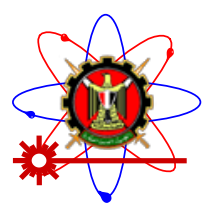

Sensitivity analysis is the assessment of the impact of changes in input values or parameters on model outputs [6]. Hence, sensitivity analysis is considered by some researches as prerequisite for model building in any setting, whether forecasting or measurements, and in any field where models are used. Quantitative sensitivity analysis is increasingly invoked for corroboration, quality assurance, and validation of modelbased analysis [7].

Sensitivity analysis can be helpful in verification of a model. Verification is a process of checking that the model is correctly implemented. If a model responds in an unacceptable way to changes in one or more inputs or parameters, then trouble-shooting efforts can be focused to identify the source of the problem. Sensitivity analysis can be used to evaluate how robust risk estimates and management strategies are to model input assumptions and can aid in identifying data collection and research needs [9-10]. Also the sensitivity analysis can be used in case of control of system behavior. Managing a system requires that we control the system. To control a system means that by altering parameters and variables, we can produce desirable output. If varying a parameter does not alter the system output (i.e. the system is insensitive to the parameter), then, that parameter is not useful for control. Therefore, sensitivity analysis can be used to identify which parameters have potential as controllers. In addition, it detects the parameters that are responsible for changing the behavior of the model from stable to unstable or chaotic case and vise versa[11].

In this paper, a new method for parameter sensitivity analysis of Chua system is presented using the concept of the $\mathrm{L}_{2}$ norm to measure the performance index to find the most efficient parameters on the systems behavior. The comparison between Sensitivity function method and the $\mathrm{L}_{2}$ norm method is explained to show the robustness of the $L_{2}$ norm method[15-16].

\section{Sensitivity Analysis Methods}

The objective of this section is to briefly review typical sensitivity analysis methods and to recommend the methods of solution to apply one or both of the case study models. Sensitivity analysis methods may be broadly classified as mathematical methods, statistical (or probabilistic) methods, and graphical methods. This classification helps in understanding applicability of sensitivity analysis methods for different types of models, and in selecting appropriate methods according to their usefulness to a decision-maker. 
Military Technical College

Kobry Elkobbah,

Cairo, Egypt

April 19-21,2016

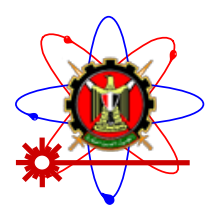

$8^{\text {th }}$ International Conference on

Mathematics and Engineering

Physics (ICMEP-8)

Mathematical methods are useful for deterministic and probabilistic models. Statistical methods are generally used for probabilistic models. Graphical methods are usually complimentary to mathematical and statistical methods. Graphical methods can be used for any kind of model [12-14].

In this paper, we can use only the mathematical method and graphical methods to predict the most critical parameter that affects the system behavior. In case of graphical method, we can use the effect of parameters changes in the behavior of output and plot this relation to show the effect of parameter changes in the output of the systems. Also, we use the variation of largest Lyapunov exponents [ 5 ]due to variation of parameters values to choose the values of parameter that change the system behavior. In the case of mathamitical method, we can use the method of sensitivity functions.

\subsection{Sensitivity functions}

In many fields of science and engineering, it is often necessary to predict the effect of some treatments or parameters on behavior of systems. Sensitivity of a dynamic system, with respect to variations of its parameters, is one of the basic aspects in the treatment of dynamic systems. One method by which the reliability of the predictions can be assessed is sensitivity analysis. The basis of all sensitivity considerations in the case of time- invariant parameter variations is the so-called sensitivity function[4],[12]. Sensitivity functions provide first order estimates for the effect of parameter variations on the system output. If the sensitivity function is known, it will be easy to calculate the change in the system behavior for a given parameter deviation.

We consider the dynamical system is given by:

$$
\frac{d x}{d t}=f(x, \alpha, t) \quad, x\left(t_{0}\right)=x_{0}
$$

where, $\alpha$ is a vector of parameters with nominal values $\alpha_{0}$ and $t_{0}$ is the initial time.

\section{Definition $1 \alpha$ - Errors (a-variations)}

$\alpha$ - errors are parameter variations around a nominal value that do not affect the order of the mathematical model. A necessary condition for errors to $\alpha$ - errors is that $\alpha_{0} \neq 0[14]$.

Because of measurement and approximation errors, the true parameter values may differ from the nominal values by $\Delta \alpha$. The resulting uncertainty in the computed state variables can be estimated by

$$
\Delta x=\int\left[f\left(x, \alpha_{0}+\Delta \alpha, t\right)-f\left(x, \alpha_{0}, t\right)\right] d
$$


Military Technical College

Kobry Elkobbah,

Cairo, Egypt

April 19-21,2016

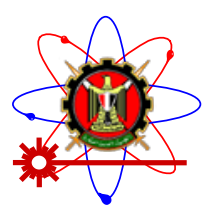

$8^{\text {th }}$ International Conference on

Mathematics and Engineering

Physics (ICMEP-8)

The mapping of the space of parameters into the state space is uniquely determined by the function $\mathrm{f}(\mathrm{x}, \alpha$, $t$ ), but this method is computationally extremely demanding for more than a few parameters [4],[12],[14]. In some cases, the errors introduced by numerical integration can introduce unacceptable inaccuracies in the solution.

This problem is usually alleviated by defining a sensitivity function $\mathrm{S}(\mathrm{t})$ that relates $\Delta \alpha$. to $\Delta \mathrm{x}$.

$$
S_{i, j}=\frac{\partial x_{i}}{\partial \alpha_{j}}
$$

$\mathrm{S}_{\mathrm{i}, \mathrm{j}}$ is a sensitivity coefficient (a partial derivative of a state variable with respect to variations in a parameter value; these quantities may vary with time ).

\section{Definition 2: Trajectory sensitivity vector}

Let the state $\mathrm{x}$ of a continuous system be a continuous function of a time invariant parameter vector $\alpha=\left[\alpha_{1} \ldots . \alpha_{\mathrm{r}}\right]^{\mathrm{T}}$. Then the partial derivative

$$
\lambda_{j}\left(t, \alpha_{0}\right)=\left.\frac{\partial \mathrm{x}(\mathrm{t}, \alpha)}{\partial \alpha_{\mathrm{j}}}\right|_{\alpha_{0}}, j=1,2, \ldots, r
$$

is called the trajectory sensitivity vector with respect to the jth parameter[14].

Note that the trajectory sensitivity vector has the same dimension as the state vector, namely $\mathrm{n}$. Its components are the trajectory sensitivity functions

$$
S_{i j}=\lambda_{i j}\left(t, \alpha_{0}\right)=\left.\frac{\partial \mathrm{x}_{\mathrm{i}}(\mathrm{t}, \alpha)}{\partial \alpha_{\mathrm{j}}}\right|_{\alpha_{0}}, i=1,2, \ldots, n, \quad j=1,2, \ldots, r
$$

Under certain conditions, $\Delta \mathrm{x}$ can be expanded about the nominal solution in a Taylor series and truncated after the first-order terms [4], [11],[12]. This is exact if the state functions are linear and autonomous. Otherwise, it is a reasonable approximation for small values of $\Delta \alpha$. The linearized sensitivity equations are

$$
\begin{gathered}
\frac{d S}{d t}=J S+\frac{\partial f}{\partial \alpha} \\
\text {, where } J=\frac{\partial f}{\partial x}
\end{gathered}
$$


Military Technical College

Kobry Elkobbah,

Cairo, Egypt

April 19-21,2016

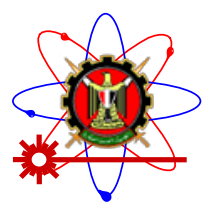

$8^{\text {th }}$ International Conference on

Mathematics and Engineering

Physics (ICMEP-8)

Where, the matrix $\mathrm{J}$ is the Jacobean matrix of the system with compatible dimensions. The partial derivatives in the above equations can rarely be calculated analytically, but they can be computed using finite differences with a sufficiently small $\Delta \alpha$. The differential equations for the sensitivity coefficients can be solved along with the state equations [4],[11].[12].

\subsubsection{The procedure for calculating the sensitivity functions}

The procedure for calculating the sensitivity functions is summarized as follows:-

1- Solve the nominal state equations for the nominal solution $\mathrm{x}\left(\mathrm{t}, \alpha_{0}\right)$

2- Evaluate the Jacobean matrices at nominal values $\mathrm{x}\left(\mathrm{t}, \alpha_{0}\right)$

$$
J=\frac{\partial f}{\partial x} \text { and } \mathrm{B}=\frac{\partial f}{\partial \alpha} \text { at } \mathrm{x}(\mathrm{t}, \alpha)=\mathrm{x}\left(\mathrm{t}, \alpha_{0}\right), \alpha=\alpha_{0}
$$

3- Combine the variation equation (6) with the original state equation (1) to obtain the augmented equation

$$
\begin{aligned}
& \frac{d x}{d t}=f(x, \alpha, t) \quad, x\left(t_{0}\right)=x_{0} \\
& S^{\bullet}=J S+\frac{\partial f}{\partial \alpha}, x_{\alpha}\left(t_{0}\right)=0
\end{aligned}
$$

4- Solve the sensitivity equations (8) for $S(t)$.

In this procedure, we need to solve or integrate the nonlinear differential equation and linear time- varying sensitivity equation with dimension $(n+n p)$, where $p$ is the number of parameters and $n$ is the dimension of the original state equation. This is not simple and it can not be computed analytically specially in the case of higher order system. We will be forced to solve these equations numerically which have some calculation problems[4],[14].

The method of L2 norm avoids there problems and finds the most efficient parameters without the need for integrations and compute the most critical parameter analytically .

\section{L2 norm method}

Norms create a new light on the notions of stability and internal stability. There are many different norms. In this section, we review the most common norms for both signals and systems. The theory of norms leads to a re-assessment of stability [4],[11],[12],[15]. 
Military Technical College

Kobry Elkobbah,

Cairo, Egypt

April 19-21,2016

\section{$8^{\text {th }}$ International Conference on Mathematics and Engineering Physics (ICMEP-8)}

\section{1 Norms of signals}

The $p$-norm for constant vectors may easily be generalized to vector-valued signals.

Definition 3 (Lp-norm of a signal)[12]. For any $1 \leq p \leq \infty$ the $p$-norm or Lp-norm $\quad\|z\|_{L p}$ of a continuoustime scalar-valued signal $z$, is define by:

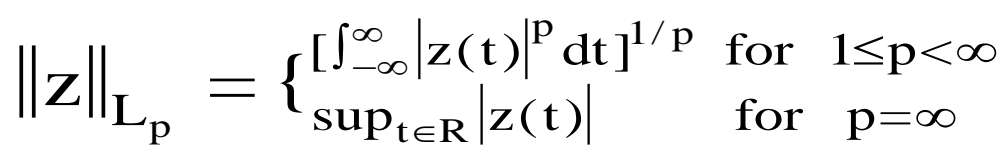

If $z(t)$ is vector-valued with values in $\mathrm{R}^{n}$ or $\mathrm{C}^{\mathrm{n}}$, this definition is generalized to

$$
\|\mathrm{Z}\|_{\mathrm{L}_{\mathrm{p}}}= \begin{cases}\left.\int_{-\infty}^{\infty}\|\mathrm{z}(\mathrm{t})\|^{\mathrm{P}} \mathrm{dt}\right]^{1 / \mathrm{p}} & \text { for } 1 \leq \mathrm{p}<\infty \\ \sup _{\mathrm{t} \in \mathrm{R}}\|\mathrm{z}(\mathrm{t})\| & \text { for } \mathrm{p}=\infty\end{cases}
$$

where, $\|Z\|$ is any norm on the $n$-dimensional space $\mathrm{R}^{n}$ or $\mathrm{C}^{\mathrm{n}}$.

The signal norms that we mostly need are the $\mathrm{L}_{2}$-norm, defined as

$$
\|\mathrm{z}\|_{\mathrm{L}_{2}}=\left(\int_{-\infty}^{\infty}\|\mathrm{z}(\mathrm{t})\|_{2}^{2} \mathrm{dt}\right)^{1 / 2}
$$

and the $\mathrm{L}_{\infty}$-norm, defined as

$$
\|\mathrm{z}\|_{\mathrm{L}_{\infty}}=\sup _{\mathrm{t} \in \mathrm{R}}\|\mathrm{z}(\mathrm{t})\|_{\infty}
$$

The square $\|z\|_{L_{2}}^{2}$ of the $L_{2}$-norm is often called the energy of the signal $z$, and the $\mathbf{L}_{\infty}$-norm $\|Z\|_{L \infty}$ its amplitude or peak value[ 22 ].

\subsection{Norms of linear systems}

Consider the system shown in Figure 1, which maps the input signal $u$ into an output signal $y$. Given an input $u$, we denote the output of the system as $y=\Phi \mathrm{u}$. If $\Phi$ is a linear operator the system is said to be linear. The norm of the system is now defined as the norm of this operator[ 22 ]. 
Military Technical College

Kobry Elkobbah,

Cairo, Egypt

April 19-21,2016

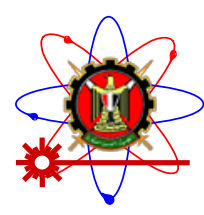

$8^{\text {th }}$ International Conference on Mathematics and Engineering Physics (ICMEP-8)

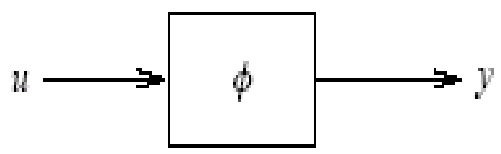

Figure. 1 Input-output mapping system

In the next section, we establish formula for the norms of a linear time-invariant system induced by the $\mathrm{L}_{2}$ norm

\subsection{1 $L_{2}$ norm of linear system}

A sensitivity measure of the time domain is to take the $L_{2}$ norm of the sensitivity vectors of system errors. This measure allows a global sensitivity characterization of the output or state.

In the following subsections, we will introduce some concept to help in calculation of the $\mathrm{L}_{2}$ norm[4],[16],[19],[21].

\section{Definition $\mathrm{L}_{2}$ norm}

The definite integral of the quadratic form,

$$
I_{M}=\int_{t}^{t_{1}} e^{T}(t) Z e(t) d t
$$

is called the $\mathrm{L}_{2}$ norm[15 ].

Where, $\mathrm{Z}$ is a symmetrical positive definite weighting matrix, $\mathrm{e}(\mathrm{t})$ is to be a set corresponding to the parameter induced trajectory or output deviation ,

$$
\mathrm{e}(\mathrm{t})=\mathrm{y}\left(\mathrm{t}, \alpha_{0}\right)-\mathrm{y}(\mathrm{t}, \alpha) \text { and } \mathrm{t}_{1}>\mathrm{t}>0 .
$$

However, the parameters are infinitesimal, time- invariant or scalar then the corresponding sensitivity vectors $\lambda\left(t, \alpha_{0}\right), \sigma\left(t, \alpha_{0}\right)$ can be used, i.e. The $L_{2}$-norm[16],[17] is given by :

$$
I_{M}=\int_{0}^{\infty} \sigma^{T}\left(t, \alpha_{0}\right) Z \sigma\left(t, \alpha_{0}\right) d t
$$

where, $\sigma\left(t, \alpha_{0}\right)$ is defined as the output sensitivity matrix with respect to ( $\alpha$ - parameters variations).

or

$$
I_{M}=\int_{0}^{\infty} \lambda^{T}\left(t, \alpha_{0}\right) Z \lambda\left(t, \alpha_{0}\right) d t
$$

where, $\lambda\left(t, \alpha_{0}\right)$ is the trajectory sensitivity vector [17] . 
Military Technical College

Kobry Elkobbah,

Cairo, Egypt

April 19-21,2016

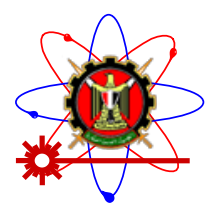

$8^{\text {th }}$ International Conference on

Mathematics and Engineering

Physics (ICMEP-8)

The special case of the $L_{2}$ norm is the so- called system error integral or the performance index [17], [18] and is given by:

$$
I_{M}=\int_{0}^{\infty} y^{2}(t, \alpha) d t
$$

The calculation of $L_{2}$ norm or performance index $J$ using the equations (14), (16) needs finding the values of $\lambda\left(\mathrm{t}, \alpha_{0}\right), \sigma\left(\mathrm{t}, \alpha_{0}\right)$ by solving the trajectory sensitivity equation analytically. This is not simple especially in higher order nonlinear system. To avoid this problem, we use the relation between the $\mathrm{L}_{2}$ norm and the Lyapunov function to calculate the value of the performance index without the need of integration.

\subsection{The relation between the Lyapunov function and the $\mathrm{L}_{2}$ norm and performance index $\mathrm{J}$}

An interesting and potentially valuable application of Lyapunov function is in the evaluation of the performance index which is quadratic in form[4],[16],[17].

\section{Theorem 1}

All the eigenvalues of the matrix $A$ have strictly negative real parts if and only if for every positive definite matrix $W>0$ there exists a positive definite solution $Y$ to the following Lyapunov matrix equation $A^{T} Y+$ $\mathrm{YA}+\mathrm{W}=0[22]$.

\section{Theorem 2}

The equilibrium state $\{0\}$ of a linear system $\mathrm{X}^{\bullet}=\mathrm{A} \mathrm{x}$ is asymptotically stable if and only if, given any symmetric positive definite matrix $\mathrm{W}$, there exists a symmetric positive definite matrix $\mathrm{Y}$ which is the unique solution of $\mathrm{W}=-\mathrm{A}^{\mathrm{T}} \mathrm{Y}+\mathrm{Y} \mathrm{A}$, and $\mathrm{V}(\mathrm{x})=\mathrm{X}^{\mathrm{T}} \mathrm{Y} \mathrm{X}$ is a Lyapunov function [4],[16],[17].

With the aid of the theorems 1, 2 and equation (17), the performance index $\mathrm{J}$ (which is equal to the $\mathrm{L}_{2}$ norm) for each parameter can be calculated as follows:

For an index

$$
J=\int_{0}^{\infty} y^{2}(t) d t \text {, with, } \mathrm{y}=\mathrm{C} \mathrm{x} \text {, where C is the output matrix }
$$

we compute 
Military Technical College

Kobry Elkobbah,

Cairo, Egypt

April 19-21,2016

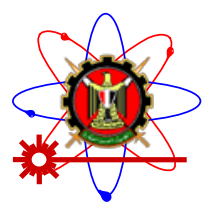

$8^{\text {th }}$ International Conference on Mathematics and Engineering

Physics (ICMEP-8)

$$
\mathrm{y}^{2}=\mathrm{X}^{\mathrm{T}} \mathrm{C}^{\mathrm{T}} \mathrm{C} \mathrm{X}=\mathrm{X}^{\mathrm{T}} \mathrm{W} \mathrm{X} \text { and thus obtain } \mathrm{W}=\mathrm{C}^{\mathrm{T}} \mathrm{C}
$$

from the definition of the Lyapunov function

$$
\mathrm{V}(\mathrm{x})=\mathrm{X}^{\mathrm{T}} \mathrm{Y} \mathrm{X}
$$

where, $\mathrm{W}=\mathrm{C}^{\mathrm{T}} \mathrm{C}$ and $\mathrm{W}=-\left(\mathrm{A}^{\mathrm{T}} \mathrm{Y}+\mathrm{Y} \mathrm{A}\right), \mathrm{W}$ is positive definite matrix

So defined matrix $\mathrm{Y}$ satisfies

$A^{T} Y+Y A=\int_{0}^{\infty} A^{T} e^{A^{T} t} C^{T} C e^{A t}+\left.e^{A^{T} t} C^{T} C e^{A t} A d F e^{A^{T} t} C^{T} C e^{A t}\right|_{t=0} ^{t=\infty}=-C^{T} C=-W$

That is, $Y$ satisfies the Lyapunov equation .

and as $A$ is a stability matrix

$$
A^{\mathrm{T}} Y+Y A=-C^{\mathrm{T}} C=-\mathrm{W},
$$

The solution $Y$ of (20) is well known to be unique. If $A$ is not a stability matrix then the output $y(t)$ is unbounded.

From the definition of the Lyapunov function for the system $\mathrm{x}^{\bullet}=\mathrm{A} \mathrm{x}$ we find,

$$
V^{\bullet}(x)=-X^{T} W X
$$

Integrating we get

$$
\int_{0}^{\infty} \frac{d V}{d t} \quad d t=-\mathrm{V}\left(\mathrm{x}_{0}\right)+\mathrm{V}(0)=-\int_{0}^{\infty} X^{2}(t) d t
$$

This integration can be computed as follow

Since the system is asymptotically stable and V $(0)=0$ then

$$
\begin{gathered}
J=\int_{0}^{\infty} X^{2}(t) d t \\
J=V\left(x_{0}\right)
\end{gathered}
$$

i.e this integration can be computed by direct substituting in the Lyapunov function $\mathrm{V}(\mathrm{x}) \mathrm{by} \mathrm{x}_{0}$ in steed of $\mathrm{x}$

$$
\mathrm{J}=\mathrm{x}_{\mathrm{o}}^{\mathrm{T}} \mathrm{Y} \mathrm{x}_{\mathrm{o}}
$$

Hence, $\mathbf{J}$ is calculated and equal to $\mathbf{L}_{2}$ norm.

Where,

$\mathrm{X}_{0} \quad$ : is the initial condition state vector.

$\mathrm{Y} \quad$ : is a symmetrical matrix calculated by solving equation (20)

w : positive definite matrix 
Military Technical College

Kobry Elkobbah,

Cairo, Egypt

April 19-21,2016

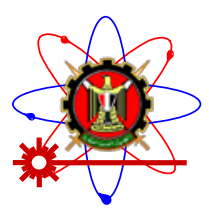

$8^{\text {th }}$ International Conference on Mathematics and Engineering

Physics (ICMEP-8)

Provided that, the system under consideration is given by its autonomous state space equations. From equation (26), $\mathrm{J}$ is determined without the need of integration and it can be determined by solving simple algebraic equation. Now, we shall introduce the algorithm for calculating the $\mathrm{L}_{2}$ norm.

3.4 The proposed algorithm for calculating $\mathrm{L}_{2}$ norm of a nonlinear system

1- Linearize the original system $\frac{d x}{d t}=\mathrm{f}(\mathrm{x}, \alpha, \mathrm{t})$ about the equilibrium point to find the equivalent linear system $\frac{d x}{d t}=\mathrm{A} x$ and setting all parameters equal to its nominal values in the matrix $\mathrm{A}$

2-Take the partial derivatives for the matrix A with the first parameter $\mathrm{B}=\frac{\frac{\partial A}{\partial \alpha_{i}}}{\left.\right|_{\alpha_{i}=\alpha_{i}(0)} \text { and then set all }}$ other all parameters equal to its nominal values

3- Find the augmented matrix $\quad \mathrm{M}=\left[\begin{array}{cc}A & 0 \\ B & A\end{array}\right]$

4-Solve the equation $\mathrm{W}=-(\mathrm{MT} \mathrm{Y}+\mathrm{Y} \mathrm{M})$ to find the unique symmetric positive definite matrix $\mathrm{Y}$ and take $\mathrm{W}=\mathrm{I}$, I Identity matrix.

5- Solve the equation $\mathrm{J}=\mathrm{x}_{\mathrm{O}}^{\mathrm{T}} \mathrm{Y} \mathrm{x}_{\mathrm{O}}$ for arbitrary initial condition $X_{0}$,where J= L2 norm 6-Repeat steps 2 to 5 for the other parameters

4. Computational results (Chua's circuit with cubic nonlinearity)

In the following section, we discuss Chua [20] model using the sensitivity function and $L_{2}$ norm. We use the scatter plot of parameters versus time as a graphical method to clarify the effect of parameter changes in the system behavior. Also, we obtain the effect of parameter variation on the system behavior and find the most effective parameter on the system

$$
\begin{aligned}
& \frac{d x}{d t}=\alpha\left(y-c x-x^{3}\right) \\
& \frac{d y}{d t}=-y+z \\
& \frac{d z}{d t}=-\beta y
\end{aligned}
$$


Military Technical College

Kobry Elkobbah,

Cairo, Egypt

April 19-21,2016

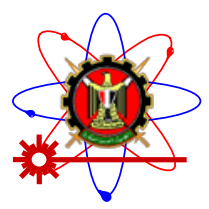

$8^{\text {th }}$ International Conference on

Mathematics and Engineering

Physics (ICMEP-8)

where, $\alpha, \beta$ and c are the parameters of Chua's circuit, and the system has three equilibrium points

$(-\sqrt{-c}, 0, \sqrt{-c}),(0,0,0),(\sqrt{-c}, 0,-\sqrt{-c})$. Letting $\alpha=10, \beta=16$ and $c=-0.143$. These values lead to the chaotic behavior namely double scroll attractor with largest Lyapunov exponent (0.1317) and shown in figure (2)

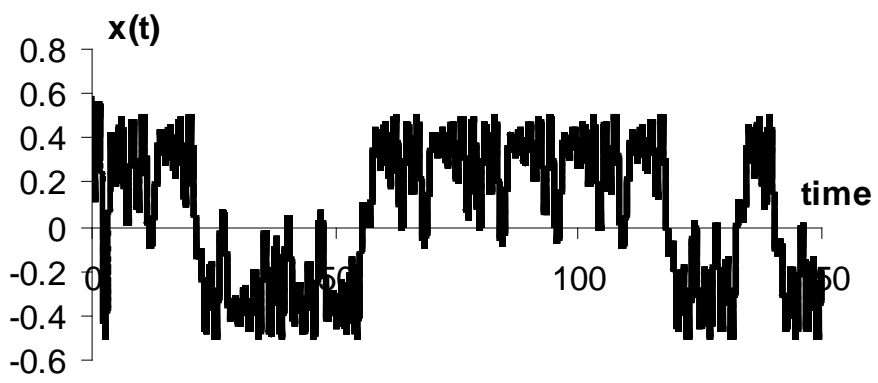

Figure 2a The time response $\mathrm{x}(\mathrm{t})$ of Chua system

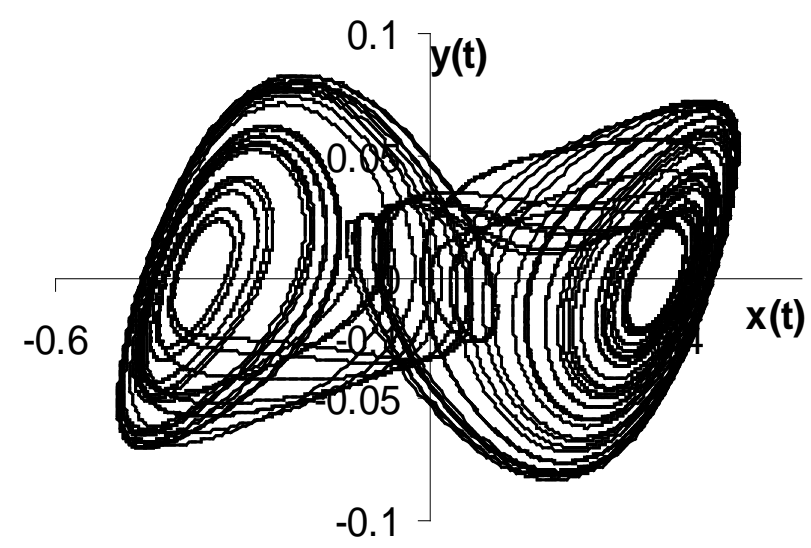

Figure (2b) The phase plane of $x(t)$ versus $y(t)$

Figure (3) show the effect of parameters variation on the value of the largest Lyapunov exponent 
Military Technical College

Kobry Elkobbah,

Cairo, Egypt

April 19-21,2016 $8^{\text {th }}$ International Conference on Mathematics and Engineering Physics (ICMEP-8)

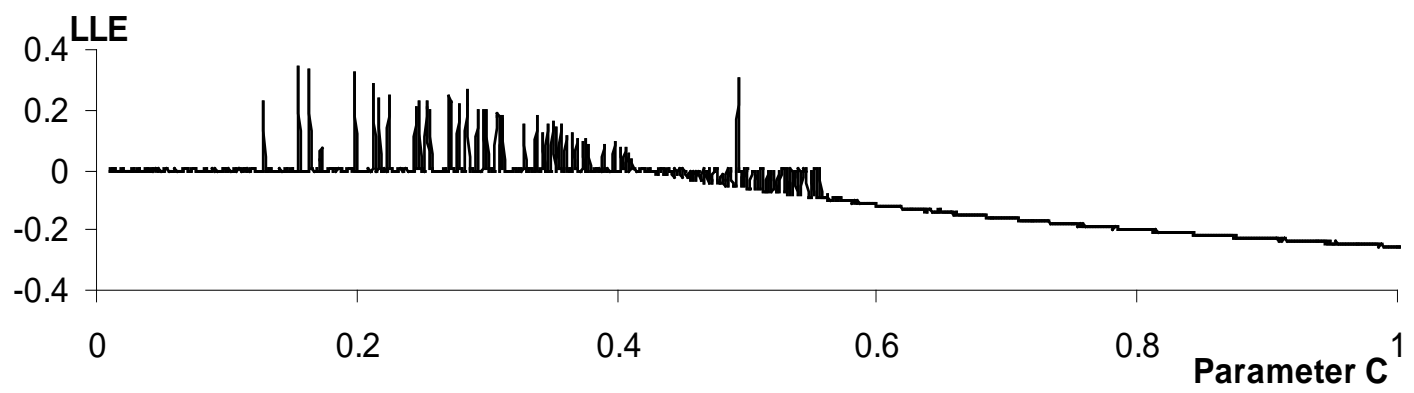

Figure (3a) The scatter plot of Lyapunov exponents Vs parameter c

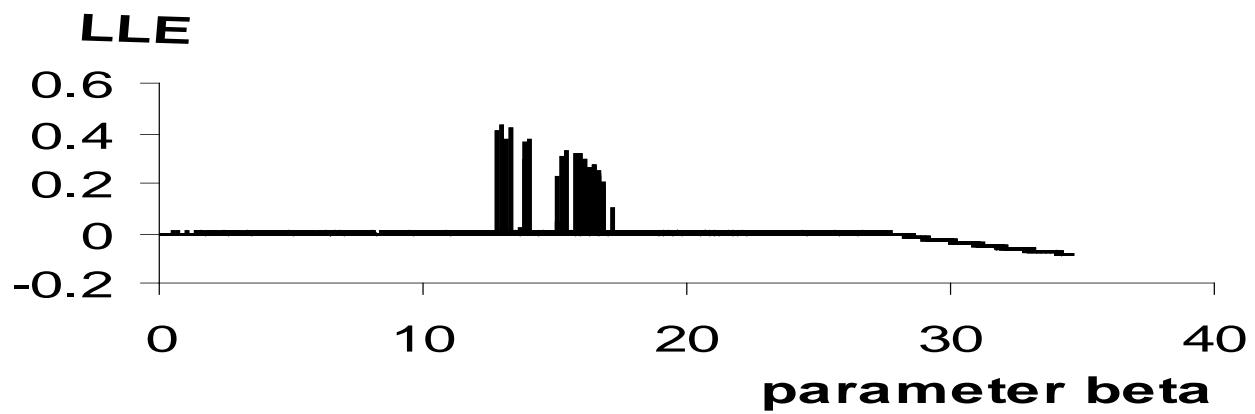

Figure (3b) The scatter plot of Lyapunov exponents Vs parameter beta

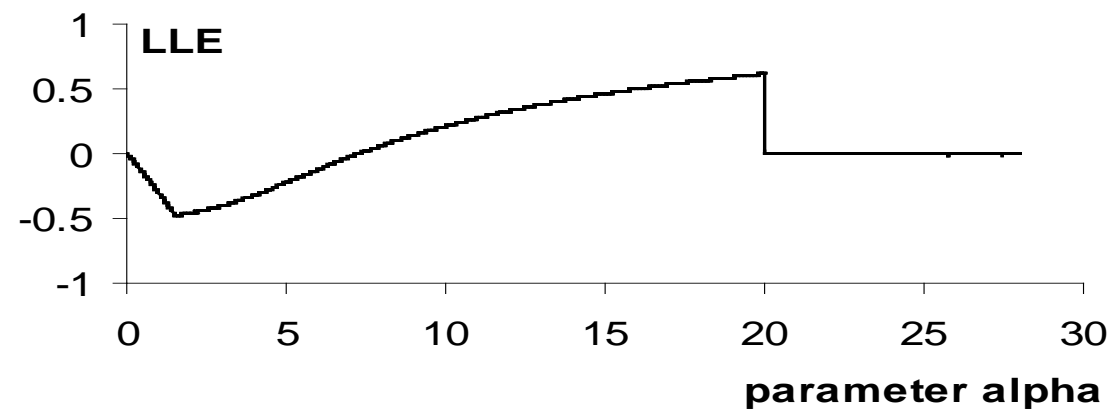

Figure (3c) The scatter plot of Lyapunov exponents Vs parameter alpha

The inspection of Figure 3 shows that the largest Lyapunov exponent is more sensitive to the variation in the parameter $\mathrm{C}$ than to variations in other parameters.

In what follows, we apply the sensitivity function method and $\mathrm{L}_{2}$ norm method on the Chua system. 
Military Technical College

Kobry Elkobbah,

Cairo, Egypt

April 19-21,2016

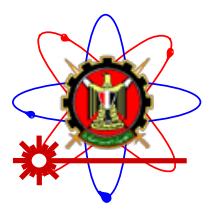

$8^{\text {th }}$ International Conference on Mathematics and Engineering

Physics (ICMEP-8)

\subsection{Sensitivity study of the Chua system using sensitivity function method}

First we use the concept of the sensitivity function to show the effect of parameter variation in the behavior of the system.

The Jacobian matrices $J=\frac{\partial f}{\partial x}$ and $\mathrm{B}=\frac{\partial f}{\partial \alpha}$ are given by

$$
\begin{aligned}
& J=\left[\begin{array}{ccc}
\alpha\left(-3 x_{1}^{2}-c\right) & \alpha & 0 \\
1 & -1 & 1 \\
0 & -\beta & 0
\end{array}\right] \\
& B=\left[\begin{array}{ccc}
x_{2}-x_{1}^{3}-c x_{1} & 0 & -\alpha x_{1} \\
0 & 0 & 0 \\
0 & -x_{2} & 0
\end{array}\right]
\end{aligned}
$$

Evaluate these Jacobian matrices at the nominal values of parameters $\alpha=\alpha_{0}=(\alpha=10, c=-0.143, \beta=16)$ to obtain

$$
J=\left[\begin{array}{ccc}
-30 x_{1}^{2}+1.430 & 10 & 0 \\
1 & -1 & 1 \\
0 & -16 & 0
\end{array}\right]
$$

and

$$
B=\left[\begin{array}{ccc}
x_{2}-x_{1}^{3}-.143 x_{1} & 0 & -10 x_{1} \\
0 & 0 & 0 \\
0 & -x_{2} & 0
\end{array}\right]
$$

to solve $\mathrm{S}(\mathrm{t})$ numerically, we solve equation (5) at the nominal values of the parameters . Let

$$
S=\left[\begin{array}{lll}
w(t) & q(t) & r(t) \\
s(t) & u(t) & v(t) \\
l(t) & n(t) & m(t)
\end{array}\right]=\left[\begin{array}{lll}
\frac{\partial x}{\partial \alpha} & \frac{\partial x}{\partial \beta} & \frac{\partial x}{\partial c} \\
\frac{\partial y}{\partial \alpha} & \frac{\partial y}{\partial \beta} & \frac{\partial y}{\partial c} \\
\frac{\partial z}{\partial \alpha} & \frac{\partial z}{\partial \beta} & \frac{\partial z}{\partial c}
\end{array}\right]
$$

Then the augmented equation (8) is given by 
Military Technical College

Kobry Elkobbah,

Cairo, Egypt

April 19-21,2016

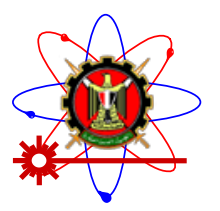

$8^{\text {th }}$ International Conference on Mathematics and Engineering

Physics (ICMEP-8)

$$
\begin{aligned}
& \frac{d x(t)}{d t}=10\left(y(t)+.0143 x(t)-x(t)^{3}\right) \\
& \frac{d y(t)}{d t}=x(t)-y(t)+z(t), \\
& \frac{d z(t)}{d t}=-16 y(t), \\
& \frac{d w(t)}{d t}=(1.43-30 x(t)) w(t)+10 s(t)+y(t)-x(t)^{3}+0.143 x(t), \\
& \frac{d q(t)}{d t}=\left(-30 x(t)^{2}+1.430\right) q(t)+10 u(t), \\
& \frac{d r(t)}{d t}=\left(-30 x(t)^{2}+1.430\right) r(t)+10 v(t)-10 x(t), \\
& \frac{d s(t)}{d t}=w(t)-s(t)+l(t), \\
& \frac{d u(t)}{d t}=q(t)-u(t)+n(t), \\
& \frac{d v(t)}{d t}=r(t)-v(t)+m(t), \\
& \frac{d m(t)}{d t}=-16 s(t), \\
& \frac{d t}{d t}=-16 u(t)-y(t), \\
& \frac{d t i n}{d t},
\end{aligned}
$$

The solution of this equation was computed for arbitrary initial conditions $\mathrm{X}_{0}=[0, \ldots, 0]^{\mathrm{T}}$.

Figure (4) shows $\mathrm{w}(\mathrm{t}), \mathrm{q}(\mathrm{t})$ and $\mathrm{r}(\mathrm{t})$, the sensitivities of $\mathrm{x}(\mathrm{t})$ with respect to $\alpha, \beta$ and $\mathrm{C}$,

Figure (5) shows $\mathrm{s}(\mathrm{t}), \mathrm{u}(\mathrm{t})$ and $\mathrm{v}(\mathrm{t})$, the sensitivities of $\mathrm{y}(\mathrm{t})$ with respect to $\alpha, \beta$ and $\mathrm{C}$ and Figure (6) shows $\mathrm{l}(\mathrm{t}), \mathrm{n}(\mathrm{t})$ and $\mathrm{m}(\mathrm{t})$, the sensitivities of $\mathrm{z}(\mathrm{t})$ with respect to $\alpha, \beta$ and $\mathrm{C}$. 
Military Technical College

Kobry Elkobbah,

Cairo, Egypt

April 19-21,2016

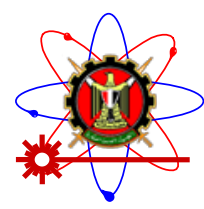

$8^{\text {th }}$ International Conference on Mathematics and Engineering

Physics (ICMEP-8)

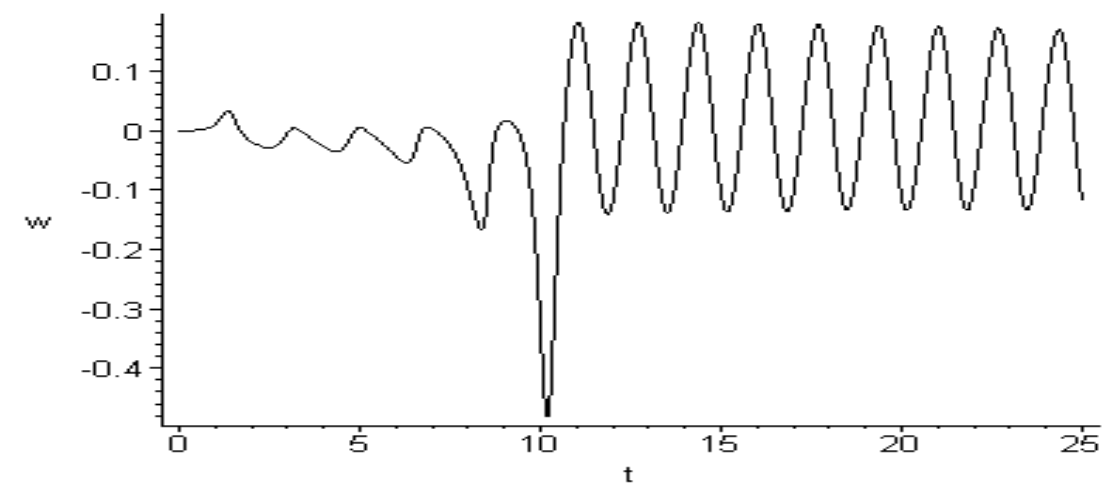

Figure 4 a The sensitivity to parameter Alpha on $\mathrm{x}(\mathrm{t})$

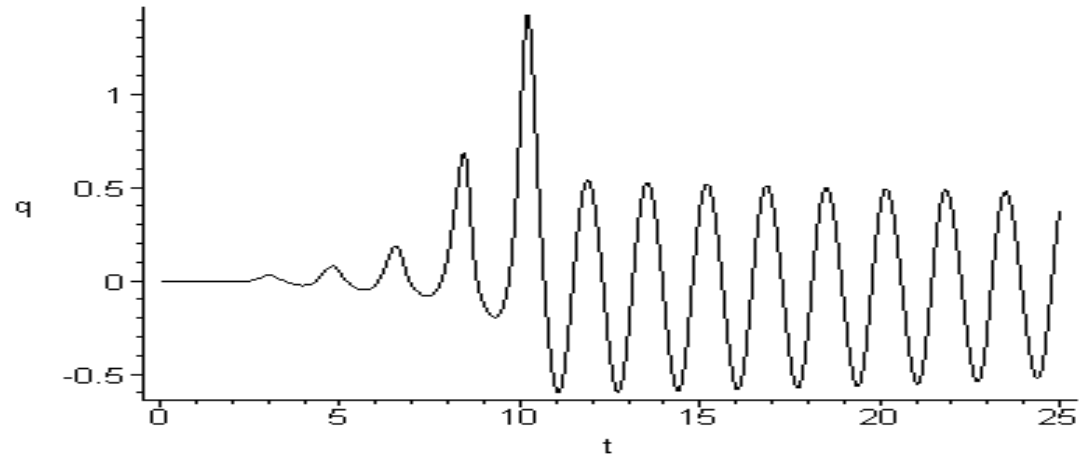

Figure $4 \mathrm{~b}$ The sensitivity to parameter beta on $\mathrm{x}(\mathrm{t})$

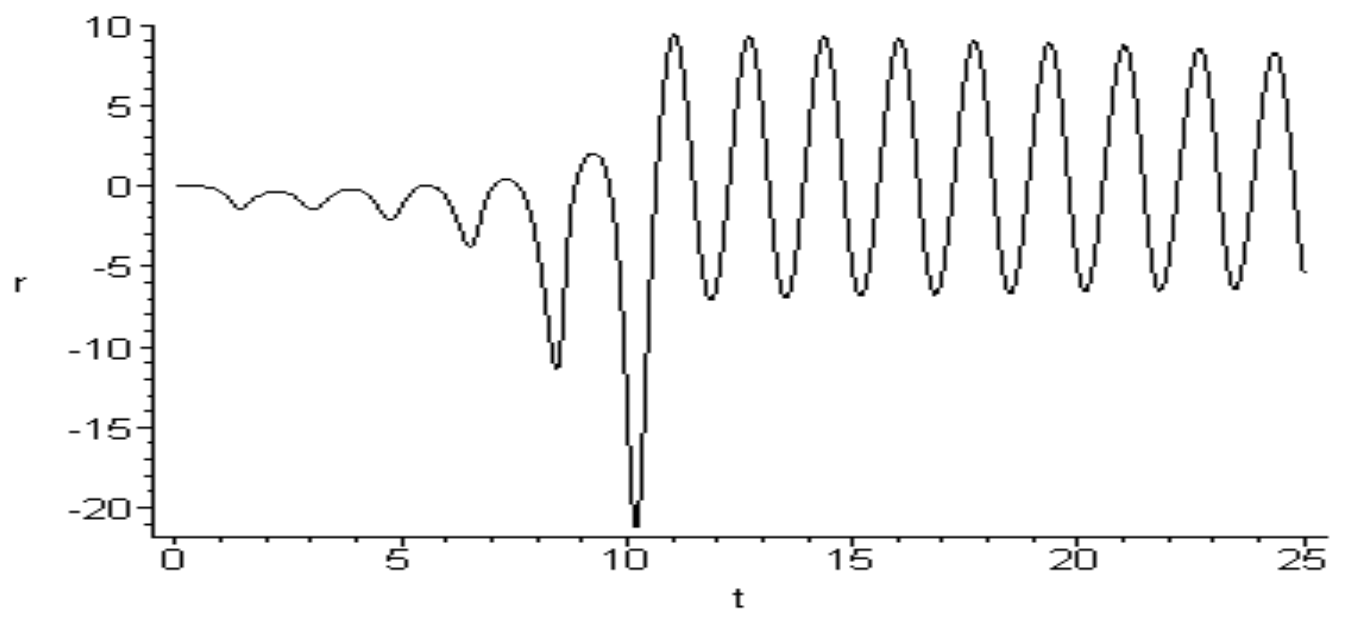

Figure 4C The sensitivity to parameter $\mathrm{C}$ on $\mathrm{x}(\mathrm{t})$ 


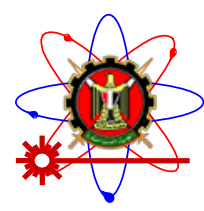

\section{$8^{\text {th }}$ International Conference on Mathematics and Engineering \\ Physics (ICMEP-8)}

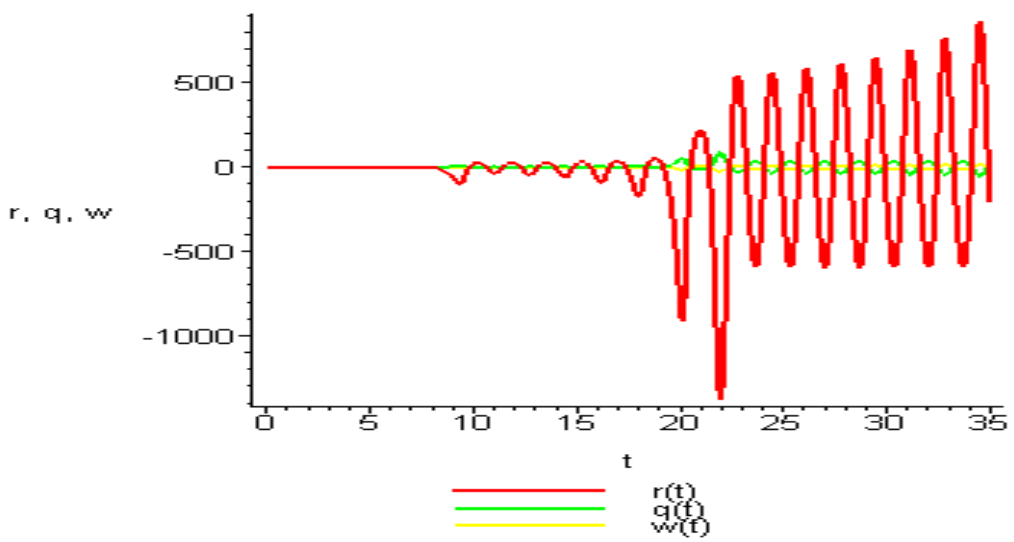

Figure 4d The sensitivities to parameter alpha, beta and C on $\mathrm{x}(\mathrm{t})$

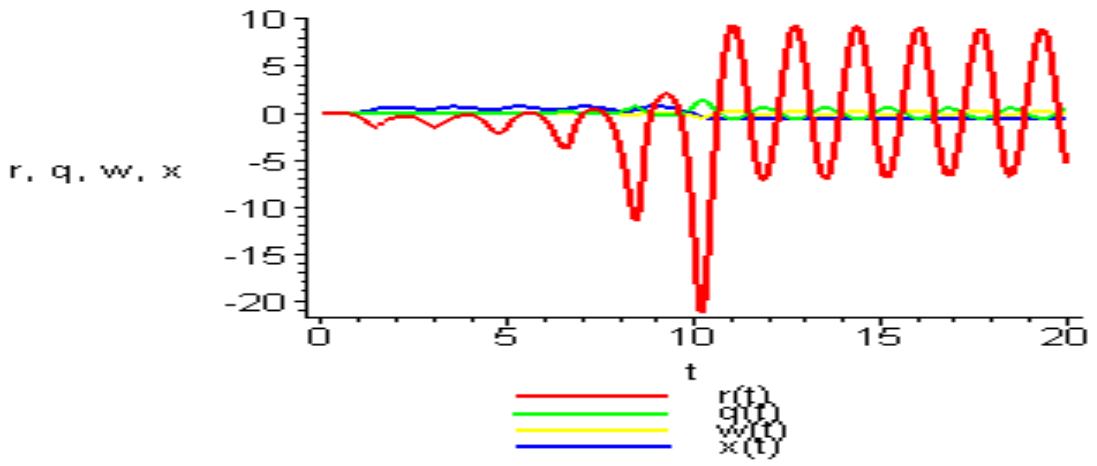

Figure $4 \mathrm{e}$ The sensitivities of parameters alpha, beta and $\mathrm{C}$ on $\mathrm{x}(\mathrm{t})$ and the solution $\mathrm{x}(\mathrm{t})$

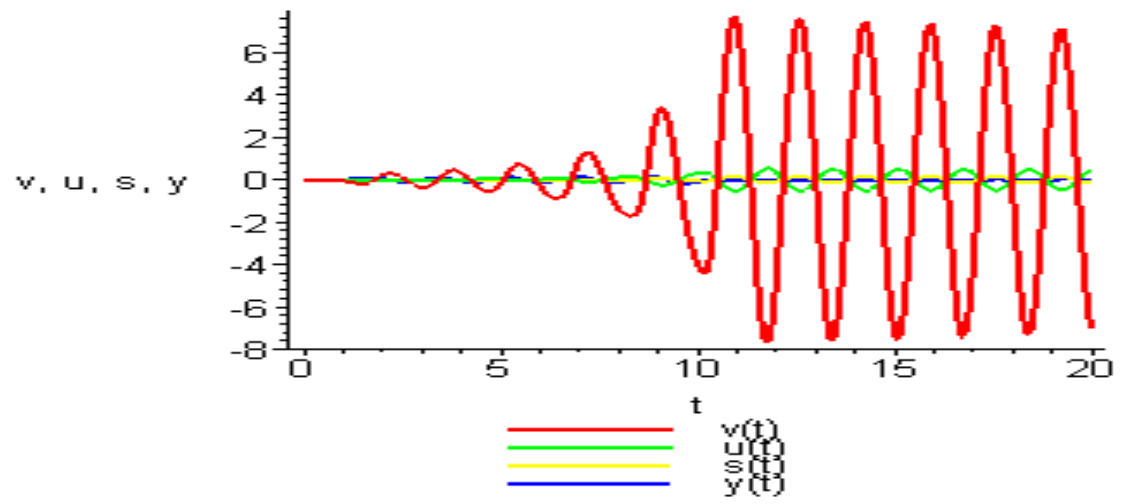

Figure 5The sensitivities of parameters alpha, beta and C on $y(t)$ and the solution $y(t)$ 


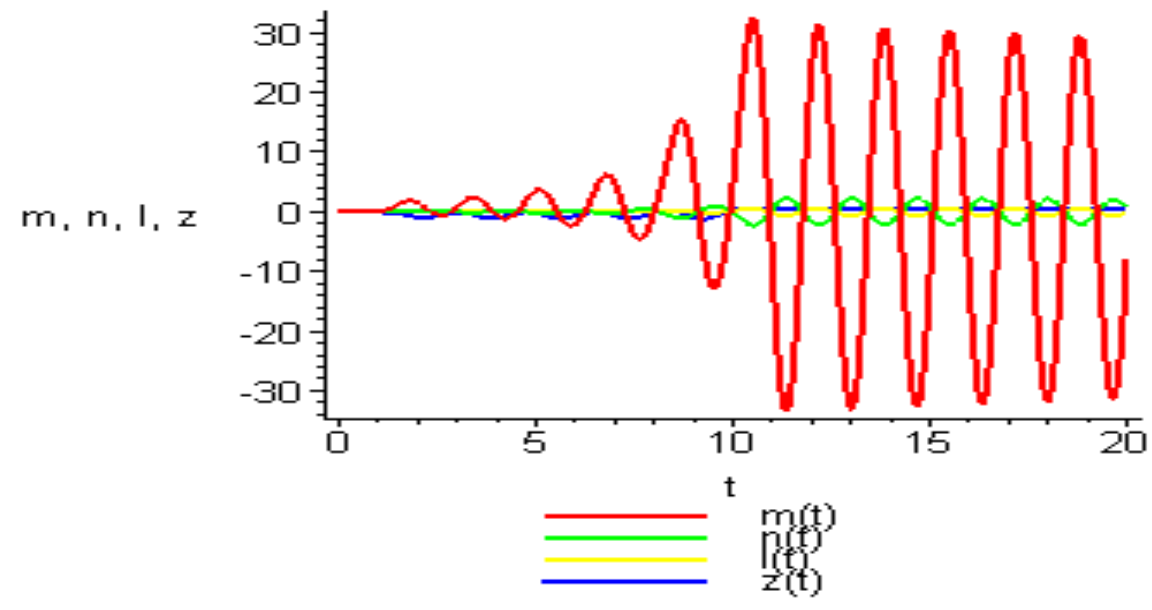

Figure 6The sensitivities of parameters alpha, beta and $\mathrm{C}$ on $\mathrm{z}(\mathrm{t})$ and the solution $\mathrm{z}(\mathrm{t})$

The inspection of Figures 4, 5 and 6 shows that the effect of parameters variation on $x(t), y(t)$ and $z(t)$ show that the solutions $x(t), y(t)$ and $z(t)$ are more sensitive to the variation in the parameter $C$ than to variations in other parameters.

\subsection{Sensitivity study of the Chua system using the proposed method}

The Chua system with cubic nonlinearity is described by the nonlinear differential equations, the model contain the parameters $\alpha^{\mathrm{T}}=\left[\begin{array}{lll}\alpha & \beta & \mathrm{c}\end{array}\right]$, their variations are considered as $\alpha$-parameter variations i.e. they vary around there nominal values and never go to zero.

\subsubsection{Sensitivity Analysis for Parameter $\alpha$}

Applying the algorithm described in section 3 to evaluate the value of $L_{2}$ norm for the parameter $\alpha$

Step 1 The matrix $A$ is evaluated at the equilibrium point $(\sqrt{-c}, 0,-\sqrt{-c})$ and the nominal values of parameters is given by

$$
A=\left[\begin{array}{crr}
-1.716000000 & 6 & 0 \\
1 & -1 & 1 \\
0 & -16 & 0
\end{array}\right]
$$


Military Technical College

Kobry Elkobbah,

Cairo, Egypt

April 19-21,2016 $8^{\text {th }}$ International Conference on Mathematics and Engineering

Physics (ICMEP-8)

Step 2 The matrix B is given by

$$
\mathrm{B}=\left[\begin{array}{ccc}
-.2860000000 & 1 & 0 \\
0 & 0 & 0 \\
0 & 0 & 0
\end{array}\right]
$$

Step 3 The matrix $M$ is given by

$$
\mathrm{M}=\left[\begin{array}{crrcrc}
-1.716000000 & 6 & 0 & 0 & 0 & 0 \\
1 & -1 & 1 & 0 & 0 & 0 \\
0 & -16 & 0 & 0 & 0 & 0 \\
-.2860000000 & 1 & 0 & -1.716000000 & 6 & 0 \\
0 & 0 & 0 & 1 & -1 & 1 \\
0 & 0 & 0 & 0 & -16 & 0
\end{array}\right]
$$

The eigenvalues of the matrix $\mathrm{M}$ are given by

$-2.47110206,-2.471102014$,

$0.1224492195+3.331041547 \mathrm{j}$,

\section{$3.331041821 \mathrm{j}$.}

i.e. all eigenvalues have negative real part and the matrix $M$ is the stability matrix[7].
$-0.12224492195+3.331041547 j$,

$-0.1224487402+3.331041821 \mathrm{j},-0.1224487402-$

Step 4 solve the matrix equation $\left(M^{T} Y+Y M\right)+W=0$, where $W=$ Identity matrix. then the matrix $\mathrm{Y}$ is given by

$\mathrm{Y}=$

$\left[\begin{array}{l}4.829056022,8.108434629,4.251109641,1.125085646,1.013752452,1.251035954 \\ 8.108434629,61.05849735,-.5000000000,3.907889578,17.69597037,2.026706671 \\ 4.251109641,-.5000000000,5.510088477,1.096260435,-2.026706671,1.643764978 \\ 1.125085646,3.907889578,1.096260435,3.707510815,5.862088559,3.124760232 \\ 1.013752452,17.69597037,-2.026706671,5.862088559,43.67253135,-.5000000000 \\ 1.251035954,2.026706671,1.643764978,3.124760232,-.5000000000,3.932568297\end{array}\right]$

The eigenvalues of the matrix $\mathrm{Y}$ are given by

0.1776467, .2043212,5.01426773,10.24221459,33.51465822,73.55716784. 
Military Technical College

Kobry Elkobbah,

Cairo, Egypt

April 19-21,2016

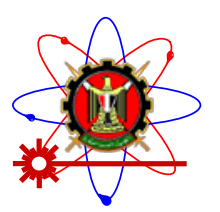

$8^{\text {th }}$ International Conference on Mathematics and Engineering Physics (ICMEP-8)

i.e. all eigenvalues of the matrix $\mathrm{Y}$ are positive and the matrix is a symmetric matrix. This leads to the deduction that the matrix is positive definite [7] and the Lyapunov function $\mathrm{V}\left(\mathrm{x}_{0}\right)$ exists and is equal to $\mathrm{X}_{0}^{\mathrm{T}} \mathrm{YX}_{0}$.

Step 5 Solve the equation $\mathrm{J}=\mathrm{X}_{0}^{\mathrm{T}} \mathrm{YX}_{0}$ for $\mathrm{X}_{0}=[1,1.2,-.015,0,0,0]$

$$
\mathrm{L}_{2}(\alpha)=\mathrm{J}=[128.8907515]
$$

Which is equal to the $L_{2}$ norm of the parameter $\alpha$.

\subsubsection{Sensitivity analysis for parameter $\beta$}

Following the same procedure we get

The matrix $\mathrm{B}$ is given by

$$
\mathrm{B}=\left[\begin{array}{rrr}
0 & 0 & 0 \\
0 & 0 & 0 \\
0 & -1 & 0
\end{array}\right]
$$

The matrix $\mathrm{M}$ is given by

$$
\mathbf{M}=\left[\begin{array}{crccrc}
-1.716000000 & 6 & 0 & 0 & 0 & 0 \\
1 & -1 & 1 & 0 & 0 & 0 \\
0 & -16 & 0 & 0 & 0 & 0 \\
0 & 0 & 0 & -1.716000000 & 6 & 0 \\
0 & 0 & 0 & 1 & -1 & 1 \\
0 & -1 & 0 & 0 & -16 & 0
\end{array}\right]
$$

The eigenvalues of the matrix $\mathrm{M}$ are given by

$$
\text { [-2.471102040, -.1224489799+3.331041639j, -.1224489799-3.331041639j, -2.471102040, }
$$

$.1224489799+3.331041639 j,-.1224489799-3.331041639 j]$ i.e all eigenvalues have negative real parts and the matrix $\mathrm{M}$ is the stability matrix.

The matrix $\mathrm{Y}$ is given by 
Military Technical College

Kobry Elkobbah,

Cairo, Egypt

April 19-21,2016 $8^{\text {th }}$ International Conference on Mathematics and Engineering Physics (ICMEP-8)

$\mathrm{Y}=\left[\begin{array}{cccccc}3.707510815 & 5.862088559 & 3.124760232 & -.3006835169 & -6.190488835 & .5649168032 \\ 5.862088559 & 43.67253135 & -.5000000000 & 5.158543005 & -2.845837490 & 7.159886069 \\ 3.124760232 & -.5000000000 & 3.932568297 & -1.166283837 & -7.159886069 & -.4135139212 \\ -.3006835169 & 5.158543005 & -1.166283837 & 5.615145668 & 9.135589966 & 5.032395085 \\ -6.190488835 & -2.845837490 & -7.159886069 & 9.135589966 & 70.47342586 & -.5000000000 \\ .5649168032 & 7.159886069 & -.4135139212 & 5.032395085 & -.5000000000 & 6.348831893\end{array}\right]$

The eigenvalues of the matrix Y are given by [.1874664181, .1929439235, 5.222046162, 8.318341516, 46.48684939, and 73.34236647]. i.e all eigenvalues of the matrix $\mathrm{Y}$ are positive and the matrix is symmetric matrix this leads to the deduction that the matrix is positive definite matrix [7] and the Lyapunov function $\mathrm{V}\left(\mathrm{x}_{0}\right)$ exists and is equal to $\mathrm{X}_{0}^{\mathrm{T}} \mathrm{YX} \mathrm{X}_{0}$.

Then

$$
\mathrm{L}_{2}(\beta)=\mathrm{J} 2=[80.59011053]
$$

Which is equal to the $L_{2}$ norm for the parameter $\beta$

\subsubsection{Sensitivity analysis for parameter c}

Repeat the same procedure as in calculation for parameter alpha and beta at the same matrix A and initial condition we get

The matrix $\mathrm{B}$ is given by

$$
\mathrm{B}=\left[\begin{array}{rrr}
-6 & 0 & 0 \\
0 & 0 & 0 \\
0 & 0 & 0
\end{array}\right]
$$

The matrix $\mathrm{M}$ is given by 
Military Technical College

Kobry Elkobbah,

Cairo, Egypt

April 19-21,2016

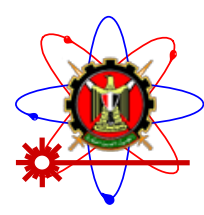

$8^{\text {th }}$ International Conference on Mathematics and Engineering Physics (ICMEP-8)

$$
\mathbf{M}=\left[\begin{array}{crrcrc}
-1.716000000 & 6 & 0 & 0 & 0 & 0 \\
1 & -1 & 1 & 0 & 0 & 0 \\
0 & -16 & 0 & 0 & 0 & 0 \\
-6 & 0 & 0 & -1.716000000 & 6 & 0 \\
0 & 0 & 0 & 1 & -1 & 1 \\
0 & 0 & 0 & 0 & -16 & 0
\end{array}\right]
$$

The eigenvalues of the matrix $\mathrm{M}$ are given by

[-2.471102040+.5637387168e-7j, -2.471102040-.5637387168e-7j, -.1224489583+3.331041571j, $.1224489583-3.331041571 \mathrm{j}, \quad-.1224490014+3.331041706 \mathrm{j}, \quad-.1224490014-3.331041706 \mathrm{j}] . \quad$ i.e $\quad$ all eigenvalues have negative real part and the matrix $\mathrm{M}$ is the stability matrix[17]

\section{The matrix $Y$ is given by}

$\left.\begin{array}{cccccc}\mathbf{Y}= & & & & \\ 200.1620625 & 346.6064475 & 161.5325127 & .6047246960 & 63.78585572 & -8.239070448 \\ 346.6064475 & 2088.138685 & -.5000000000 & -39.46537567 & 72.96144014 & -59.17553922 \\ 161.5325127 & -.5000000000 & 191.1146101 & 11.48610929 & 59.17553922 & 5.168909792 \\ .6047246960 & -39.46537567 & 11.48610929 & 3.707510815 & 5.862088559 & 3.124760232 \\ 63.78585572 & 72.96144014 & 59.17553922 & 5.862088559 & 43.67253135 & -.5000000000 \\ -8.239070448 & -59.17553922 & 5.168909792 & 3.124760232 & -.5000000000 & 3.932568297\end{array}\right]$

The eigenvalues of the matrix Y are given by [.1129812699, .5526216190, 6.478166924, 21.88211592, 345.8708798, 2155.831203]. i.e. all eigenvalues of the matrix $\mathrm{Y}$ are positive and the matrix is symmetric matrix this leads to the deduction that the matrix is positive definite matrix [18] and the Lyapunov function $\mathrm{V}\left(\mathrm{x}_{0}\right)$ exists and equal to $\mathrm{X}_{0}^{\mathrm{T}} \mathrm{YX}_{0}$.

Then

$$
\mathrm{L}_{2}(\mathrm{c})=\mathrm{J} 2=[4034.152269]
$$


Military Technical College

Kobry Elkobbah,

Cairo, Egypt

April 19-21,2016 $8^{\text {th }}$ International Conference on

Mathematics and Engineering

Physics (ICMEP-8)

Which is equal to the $\mathrm{L}_{2}$ norm for the parameter $\mathrm{C}$.

The $\mathrm{L}_{2}$ norm is calculated for each parameter and the result is depicted in the Table 1

\begin{tabular}{|c|c|c|c||}
\hline parameter & Alpha & Beta & C \\
\hline $\mathrm{L}_{2}$ norm & 128.8907515 & 80.59011053 & 4034.152269 \\
\hline $\begin{array}{c}\text { Cup time(sec) } \\
\text { (Maple 12) }\end{array}$ & 10.1 & 11.9 & 8.6 \\
\hline
\end{tabular}

Table 1 The values of $\mathrm{L}_{2}$ - norm against the model parameters of Chua model using proposed method

From table 1 it is clear that the most critical parameter (the parameter that has greatest influence on the system output) is the $C$ parameter. The results are in agreement with results of the sensitivity function.

\section{Conclusion}

When qualitative estimates of sensitivity are desired, a mathematical model of phenomena is desired or at least a relationship is required. However, such a model brings the questions concerning stability, optimality, sensitivity, and so forth.

In this work, we concentrated only on the parameter sensitivity of Chua equations. As we saw in the small application, it is possible to determine effects of parameters on model variables so that we can eliminate the less effective ones. Robustness can also be verified in comparison between two methods.

The method of $\mathrm{L}_{2}$ norm is a more simple method than the method of sensitivity function for calculating the most efficient parameter among other system parameters. In the use of the sensitivity function method, we need to solve a system of differential equations compatible with the number of parameters in the system. Also it depends on the dimension of the parameter space and takes large time to solve.

The solution of the sensitivity equation takes a total time of 112.2 second in case of Chua system. This problem is avoid by using the concept of $\mathrm{L}_{2}$ norm, which dose need to solve a system of differential equations but a set of simple algebraic equations, and take time less than the method of sensitivity function ,which takes about 30.6 seconds.

This enables us to control the chaotic dynamical system. This method is efficient if study higher order chaotic systems. 
Military Technical College

Kobry Elkobbah,

Cairo, Egypt

April 19-21,2016

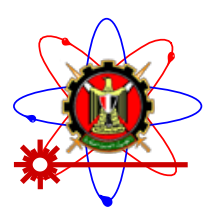

$8^{\text {th }}$ International Conference on

Mathematics and Engineering

Physics (ICMEP-8)

\section{References}

[1] S. Li, L. Petzold, and W. Zhu, "Sensitivity analysis of differential-algebraic equations: a comparison of methods on a special problem,” Applied Numerical Mathematics, vol. 32, no. 2, pp. 161-174, 2000

[2] P. Zhou and R. Ding, "Control and synchronization of the fractional-order Lorenz chaotic system via fractional-order derivative," Mathematical Problems in Engineering, vol. 2012, Article ID 214169, 14 pages, 2012.

[3] E. P. T. Cari, E. A. R. Theodoro, A. P. Mijolaro, N. G. Bretas, and L. F. C. Alberto, "Trajectory sensitivity method and master-slave synchronization to estimate parameters of nonlinear systems," Mathematical Problems in Engineering, vol. 2009, Article ID 387317, 14 pages, 2009.

[4] P. Gelndinning, Stability, Instability and Chaos: An Introduction to the Theory of Nonlinear Differential Equations, Cambridge Texts in Applied Mathematics, 1994.

[ 5] J. Guckenheimer and P. Holmes. Nonlinear Oscillations, Dynamical Systems and Bifurcations of Vector Fields, volume 42 of Applied Mathematical Sciences. Springer Verlag, New York, 1983

[6] S. Boccaletti, C. Grebogi, Y.-C. Lai, H. Mancini, and D. Maza. The control of chaos: Theory and applications. Physics Reports, 329:103-197, 2000.

[7] Juergen Kurths, S. Boccaletti, C. Grebogi and Y.-C. Lai "Introduction: Control and synchronization in chaotic dynamical systems” Chaos, Vol. 13, No. 1, 126-127,2003

[8] A. Huang, L, Pivka, C. W. Wu and M. Franz, .Chua's equation with cubic nonlinearity,. Int. J.Bifurcation and Chaos, vol. 6, pp. 2175-2222, 1996.

[9] J.C.Sprott, "Numerical calculation of Largest Lyapunov exponent”october13, 1998.

[10] Frank, P. M., Introduction to System Sensitivity Theory, Academic Press, 1978.

[11] Cacuci, D. G., Sensitivity Theory for Nonlinear Systems. I. Nonlinear Functional Analysis Approach, J. Math. Phys., 22, 2794; 1981;

[12] Cacuci, D. G., Sensitivity Theory for Nonlinear Systems. II . Extensions to Additional Classes of Responses. Math. Phys., 22, 2803; 1981.

[13] Okko H. Bosgra, Huibert Kwakernaak and Gjerrit Meinsma.” Design Methods For Control Systems" Notes for a course of the Dutch Institute of Systems and Control Winter term ,2004

[14] Sobol, I.M., "Sensitivity Estimates for Nonlinear Mathematical Models," Mathematica Modeling and Computation, 1(4): 407-414. 1993

[15] Frey, H.C., "Introduction to Special Section on Sensitivity Analysis and Summary of NCSU/USDA Workshop on Sensitivity Analysis,” Risk Analysis, 22(3): 539545,2002 [16]Frey, H.C., and R. Patil , "Identification and Review of Sensitivity Analysis Methods,"Risk Analysis, 22(3): 553-577, 2002

[17] Cullen, A.C., and H.C. Frey. Probabilistic Techniques in Exposure Assessment. PlenumPress: New York. 1999

[18] Fethi. Belkhouche,' An $\mathrm{L}_{2}$ Norm Trajectory-Based Local Linearization for Low Order Systems"' Journal of Nonlinear Mathematical Physics Volume 12, Number 1 (2005), 53-72 Article 
Military Technical College

Kobry Elkobbah,

Cairo, Egypt

April 19-21,2016

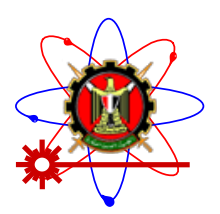

$8^{\text {th }}$ International Conference on Mathematics and Engineering Physics (ICMEP-8)

[19] B. R. Andrievskii and A. L. Fradkov "Control of Chaos: Methods and applications. II. Applications” Automation and Remote Control, Vol. 65, No. 4, 2004, pp. 505533.

[20] B. R. Andrievskii and A. L. Fradkov "Control of Chaos: Methods and Applications. I. Methods" Automation and Remote Control, Vol. 64, No. 5, 2003, pp. 673-713

[21] Daniel J. Gauthie “Controlling chaos” Am. J. Phys. 71 -8!, August 2003

[22] Khalil, H. K. “Nonlinear Systems”, 2nd edition (Prentice Hall, NJ).1996 